ÉGYPTE

monde arabe

\section{Égypte/Monde arabe}

$7 \mid 1991$

Perceptions de la centralité de l'Égypte 1

\title{
Youssef Idris : Un style singulier
}

(extraits divers)

\section{OpenEdition}

\section{Journals}

Édition électronique

URL : https://journals.openedition.org/ema/1187

DOI : 10.4000/ema. 1187

ISSN : 2090-7273

Éditeur

CEDEJ - Centre d'études et de documentation économiques juridiques et sociales

Édition imprimée

Date de publication : 30 septembre 1991

Pagination : 169-174

ISSN : 1110-5097

Référence électronique

«Youssef Idris : Un style singulier », Égypte/Monde arabe [En ligne], 7| 1991, mis en ligne le 08 juillet 2008, consulté le 07 juillet 2022. URL : http://journals.openedition.org/ema/1187 ; DOI : https:// doi.org/10.4000/ema. 1187

Ce document a été généré automatiquement le 7 juillet 2022

Tous droits réservés 


\section{Youssef Idris : Un style singulier}

(extraits divers)

\section{NOTE DE L'ÉDITEUR}

Traduit de l'arabe par Dina al-Khouli

Traduit de l'arabe par Siham Djafer

\section{Chukrî Muhammad 'lyâd, al-Musawwar n’ 3487, 9 août 1991}

1 [...] Youssef Idris possède un style particulier qui surprend au premier abord par sa «spontanéité »: cette caractéristique n'est-elle pas ce à quoi tout artiste ne recourt qu'en dernier ressort? La vie littéraire d'Idris a commencé par une phase assez méconnue où il proposait ses écrits à la revue al-Qissa («La nouvelle»), qui avait pour rédacteur en chef, dans les années cinquante, le poète Ibrâhîm Nâgî. Le critique Ahmad 'Abbâs Sâlih, qui prit connaissance de quelques-uns de ces textes, n'y trouva, à l'époque, aucun intérêt, alors qu'il a toujours eu le flair pour détecter un talent original. Faut-il en conclure que Youssef Idris - à l'instar de nombre d'écrivains n'avait en fait eu recours à la « spontanéité » qu'après s'être essayé sans succès au style littéraire prisé à l'époque?

2 Deux sortes de styles dominaient alors l'art de la nouvelle - forme qu'avait élue Youssef Idris et dans laquelle il excellait : celui de Mahmûd Taymûr, lequel, après son élection à l'académie - ou peut-être à l'époque où il s'apprêtait à y entrer - commencera à soigner en priorité le classicisme de son style. Cette préoccupation ira chez lui jusqu'à «traduire» ses anciennes oeuvres, écrites au début dans un style descriptif, en harmonie avec son souci du réalisme, en ce nouveau classicisme qu'il entendait faire sien.

3 L'autre style se rapproche de ce que Tawfîq al-Hakîm baptisera plus tard «la langue médiane », un arabe littéraire et familier à la fois. Al-Hakîm a lui-même joué un rôle 
appréciable dans le développement de ce style, qui caractérisait les récits qu'on publiait alors dans divers quotidiens et revues.

4 Le conflit qui a toujours opposé arabe classique et arabe dialectal s'obstinait à resurgir dans notre littérature moderne. Le problème semblait concerner surtout le dialogue. Il était entendu que la narration devait être en arabe littéraire; ou bien l'on écrirait le récit tout entier en dialecte, entendu comme « langue » différente du classique : c'était le parti pris de ceux qui soutenaient que le dialecte devait devenir, exclusivement, la langue de la littérature. Parmi les écrivains - il est vrai, peu nombreux - qui ont suivi ce courant, l'on trouve à ma connaissance Mustafa Mucharafa, Muhammad 'Afifi et Badr Nacha'ât. Je n'en connais pas d'autres.

Quand à la «langue médiane ", c'était finalement une langue dont étaient absentes aussi bien les saveurs de l'arabe littéraire que celles de l'arabe dialectal et qui ne convenait plus qu'à des modestes niveaux d'expression.

6 Au début de sa carrière, Youssef Idris fut peut-être quelque peu ballotté entre ces deux styles que, mû par une sorte d'intuition, il rejeta l'un et l'autre assez rapidement. Il n'avait jamais fait d'études littéraires, n'avait jamais eu à ses côtés de critique cultivé et ouvert qui l'eût aidé à éviter certains écueils (bien sûr, il y avait Mandûr et Louis 'Awad, mais le problème de la langue ne les intéressait que modérément).

7 La voie que suivit finalement Youssef Idris n'était venue à l'esprit de personne. Il s'agissait de rédiger d'abord en langue parlée plutôt qu'en langue écrite. Mais ne voulant pas écrire en arabe dialectal, il s'empressa de briser la barrière qui opposait dialecte et classique en coulant la langue parlée dans le moule littéraire, même si, pour ce faire, il devait briser quelques règles, plus ou moins consciemment.

Je ne crois pas qu'ldris connaissait le mot d'Eliot selon lequel la poésie doit être parsemée d'expressions du langage parlé. Je ne crois pas non plus qu'il avait d'autre issue; la langue littéraire était pour lui, comme pour la plupart des profanes, une langue quasi-étrangère qu'il lui était difficile - n'en étant pas assez familier d'accorder au rythme du langage parlé. Cette attitude envers les "problèmes » de la langue littéraire demeura même après qu'il eut acquis une certaine notoriété.

9 Je me souviens d'une émission radiophonique au cours de laquelle nous discutions, Youssef Idris et moi, de son roman Al-harâm en présence de Rachâd Ruchdî (qui appelait avec enthousiasme à utiliser le dialecte quoique lui-même utilisât la langue médiane dans ses écrits...) ; j'ai déclaré à Youssef que sa langue, notamment dans Al-harâm, laissait bien souvent à désirer. Je ne faisais pas seulement allusion aux erreurs grammaticales, mais c'est ce que comprirent mes interlocuteurs: Rachâd Ruchdî observa qu'il existait une solution fort simple, faire corriger le manuscrit avant publication. Il ne me vint alors d'autre exemple, pour expliquer mon point de vue, que celui du violoniste qui, tandis qu'il joue de la main droite, ajuste de la gauche les cordes de l'archet.

10 Le passage de la langue parlée à la langue écrite était pour Youssef Idriss un choix conforme à ses aptitudes personnelles et la meilleure solution qu'il eût trouvée à son problème d'écriture. Notre génie n'était pas le premier à transformer ses faiblesses en force, si l'on peut qualifier de faiblesse le talent de Youssef en matière de langue parlée ; réservons ce terme à son dédain de la prose arabe, si riche de possibilités ; car à part cela, il était passé maître dans la métamorphose du langage quotidien en une langue superbe, ce qui représente un apport majeur à la littérature arabe. 
11 Pour en revenir à la discussion qui nous opposa, je voulais seulement dire que le langage parlé ne pouvait couvrir à lui seul le champ de l'écriture littéraire: la dimension épique de l'œuvre d'Idris ne pouvait se contenter des limites du langage parlé et l'écrivain se devait d'exploiter avec adresse toutes les nuances de la langue arabe.

12 Mais cette lacune est sans importance, car l'épopée héroïque, chez Youssef Idris, a son caractère singulier, elle s'enracine dans une terre de pauvreté, de maladie et de privations ; elle a montré sa face la plus sombre dans l'existence des Egyptiens lorsque, dans les années cinquante et soixante, l'on a cru voir se manifester les signes annonciateurs d'épopées à venir qui se sont révélés n'avoir été que leurres.

$[\ldots]$

\section{Youssef Idris, al-Hilâl, août 1991}

14 "[...] La plupart du temps, je ne rédige qu'un seul brouillon, puis je commence à le "mettre au propre", je corrige et... il en sort une histoire différente. C'est d'ailleurs pour cela qu'avant d'écrire, je réfléchis longuement. L'histoire parvient à maturité avant d'être écrite. Aussi m'est-il difficile de m'installer pour écrire. Souvent, les histoires que je réécris se flétrissent. C'est pourquoi je crois que les meilleures histoires sont celles issues de la première inspiration... Leur titre est d'ailleurs simple, comme pour Nazara ("Regard") récit que j'ai écrit en dix minutes. Il y a une histoire plus courte encore intitulée Al-kanz ("Le trésor") que j'ai réécrite plus de vingt fois et qui, malgré cela, ne me satisfait pas. J'ai écrit la pièce Al-farâfîr ("Les vagabonds") d'un seul jet à l'exception du deuxième acte, qui m'a pris un temps considérable.

Chaque écrivain a ses habitudes en matière d'écriture. Quand j'écris des pièces et des nouvelles, j'enfile volontiers mon pyjama et souvent, je ne me mets à écrire que tard dans la nuit. Il faut que j'aie consacré beaucoup de temps à me préparer à écrire, en écoutant de la musique pendant un bon moment, parfois en écoutant tel morceau au moins vingt fois comme si j'essayais de convoquer les esprits, ou bien je lis un ouvrage scientifique - j'apprécie particulièrement les ouvrages de physique.

16 J'écris souvent sur un papier particulier, du papier journal brun de grand format, j'avale de grandes tasses de café et j'ai besoin d'avoir sous la main une bonne quantité de cigarettes.

17 J'accorde beaucoup d'importance à la première phrase car c'est elle qui définit le sens et le rythme de la langue que je vais utiliser et le genre de prose dans laquelle je vais m'immerger. C'est pourquoi la première page exige tant de temps. Souvent, je m'"échauffe" en écrivant une lettre à un parent du village ou à mon frère, j'écris ainsi jusqu'à éprouver le sentiment que je maîtrise mon art. [...]»

\section{Al-Tahir Muhammad Mekki,al-Hilâl, août 1991}

Ce qui était le plus faible chez lui était la langue. Laissons de côté sa conception du langage théâtral, qu'il avait exprimée dans l'introduction d'une de ses pièces: il écrivait une pièce pour qu'elle soit jouée, disait-il, et non pas lue, épargnant par conséquent au metteur en scène l'effort de "traduire » un texte littéraire en langage parlé.

Égypte/Monde arabe, 7 | 1991 
La langue qu'il utilisait dans ses nouvelles et romans, surtout dans la première étape de sa vie littéraire, se distinguait par la spontanéité. Dès lors, ce n'est pas un style classique, on y trouve beaucoup d'erreurs lexicales et elle est imprégnée de nombreuses expressions dialectales et de constructions étrangères à l'arabe. Je perçois dans cette orientation la doctrine qu'il avait faite sienne et qui allait dans le sens du poète $\mathrm{Abu}$ Tamam : "A nous de parler, à vous de commenter », avait déclaré ce dernier au groupe de critiques qui lui reprochaient la structure complexe de ses phrases. Cela aurait été chose facile pour Idris de confier sa pièce à un correcteur, mais elle ne l'aurait plus reflété tout à fait.

21 Il est vrai que maints écrivains de renommée internationale créent leur propre langue en faisant fi des règles. Mais le problème n'est pas si simple: le narrateur qui ne maitrise pas sa langue s'engage dans une voie périlleuse, eu égard à la relation particulière qui lie la langue et l'art de la narration. Le style de Youssef Idris se ressent d'un tel manque de maîtrise, c'est un style relâché, sans harmonie, sans finesse, dénué de la séduction qu'exerce une expression à la fois dense et profonde. Pour émouvoir et attirer le lecteur, il s'appuie sur la tension que créent les événements. Il demeure que cette langue est le reflet de l'expression arabe d'une époque sur laquelle se pencheront les chercheurs, les linguistes et les grammairiens au cours des prochains années.

[...]

\section{Muhammad al-Mansi Qandîl, al-Hilâl, août 1991}

\section{$[\ldots]$}

Le grand écrivain 'Abd Allah al Toukhi m'a confié une chose étrange : il était tombé sur un des premiers brouillons d'une nouvelle de Youssef Idris et il avait découvert qu'elle avait été entièrement écrite en arabe dialectal, comme s'il la racontait à un groupe de gens. Puis il la réécrivait - ou plutôt la «traduisait » - en langue classique. Peut-être était-ce là un des secrets du dynamisme puissant qui émanait de chaque ligne de ses écrits. En fait, il rédigeait dans la langue des gens qu'il décrivait, cela dans un élan égal de spontanéité et de minutie, négligeant dans une première étape les exigences du « métier » pour n'y revenir qu'ensuite.

J'ai essayé à mon tour d'emprunter cette voie, qui m'avait enthousiasmé ; j'ai échoué, évidemment... Chaque écrivain a ses secrets... C'était peut-être là la raison de son attachement au patrimoine oral et de son éloignement du patrimoine écrit. C'était l'écrivain le moins attaché à l'héritage culturel arabe, et sans aucun doute le plus proche du patrimoine oral du peuple égyptien. Le monde rural égyptien était son univers de prédilection bien qu'il eût vécu en ville plusieurs années. Les ténèbres de la campagne étaient ancrées au plus profond de lui et les voix de la Nadâha (la sirène) continuaient de le captiver dès qu'il essayait de s'en libérer. Le colporteur le poussait à une errance sans fin. Le cheykh Cheykha connaissait tous les secrets mais ne pouvait que feindre l'idiotie ou la folie... Les paysans criaient famine mais rien ne tombait du ciel. Tout ce patrimoine, Youssef Idris le portait dans son coeur comme une amulette qui donnait à son œuvre sa couleur singulière, sa saveur particulière. Nombreux sont ceux qui ont écrit sur cette campagne triste, ce paradis perdu dont les rivières, loin d'être « de lait et de miel », sont infestées de parasites. 
Mais qu'en est-il de ce patrimoine arabe qui lui léguait les éléments avec lesquels il exprimait ses tristesses et ses rêves? Un jour, je lui ai posé la question: «Tu es l'écrivain qui porte le moins d'intérêt à cet aspect du patrimoine... » Il répondit : Tu serais surpris de savoir que j'ai longtemps pensé écrire une pièce sur le poète AlMutanabbî. » Je répliquai : «Parce qu'il te ressemble ». Il reprit : « Parce qu'il ressemble à tous les vrais écrivains... Dans chaque écrivain il y a une part d'Al-Mutanabbî, chacun essaie de créer son propre mythe. Al-Mutanabbî, lui, a crée le sien propre, celui des chevaux et de la steppe... Il s'est tu un court instant puis : «Sais-tu comment est mort Al-Mutanabbî? Des brigands l'ont attaqué en chemin; un seul de ses serviteurs l'accompagnait, qui a regardé la scène sans intervenir ni crier à l'aide. Sais-tu pourquoi ? Eh bien, il avait cru au mythe de son maître ; il avait cru qu'Al-Mutanabbî était, comme il le disait dans ses poèmes, invincible, et qu'il pourrait combattre seul tous les brigands ; même après sa mort, le serviteur est resté à ses côtés, attendant sa résurrection. Chaque écrivain a son mythe... »

Il y a chez Youssef Idris quelque chose d'étrange qui ne peut que troubler l'admiration qu'on lui porte. D'une manière générale, ce n'est pas un écrivain commode. Il vous divertit parfois mais vous fait payer le prix de ce divertissement. Il aime déranger. Il sait que là réside la vérité et qu'elle a davantage de prix que l'apparence... en fait, peu lui chaut de gagner la satisfaction du lecteur, d'autant qu'il essaie de le choquer : peutêtre les ondes de ce choc feront-elles naître une autre vision. Il a assisté longtemps, lors de la Foire du livre, à des colloques agités où l'on voyait s'allonger d'année en année la liste des accusations formulées à son encontre, et le dernier colloque avait bien failli se terminer en pugilat. Mais il était tout à fait conscient de ce qu'il faisait car il se trouvait avec des gens qui sommeillaient depuis longtemps et se laissaient aller...

Je sais de lui bien d'autres choses que je tairai... Tout écrivain, du plus grand au plus modeste, a ses secrets.

INDEX

Mots-clés : Idris (Youssef), littérature 